\title{
Unbalanced Language Contact and the Struggle for Survival: Bridging Diachronic and Synchronic Perspectives on Nahuatl
}

\author{
JUST YNA OLKO
}

Faculty of 'Artes Liberales', University of Warsaw, Dobra 72, 00-312 Warszawa, Poland. Email: jolko@al.uw.edu.pl

Looking at the Spanish impact on Nahuatl both in its full historical trajectory and modern synchronic dimension, I focus on the differentiation between 'balanced', longterm language contact and 'unbalanced' contact leading to rapid language shift in contemporary indigenous communities. I discuss the connection between accelerated contact-induced language change and language endangerment and shift, highlighting and assessing the mutually interdependent extra- and inter-linguistic variables that influence and shape both processes. Of special importance is the synchronic variation linked to speakers' proficiency that influences language transmission in the diachronic perspective. On the basis of extensive fieldwork and linguistic documentation I identify several types of Nahuatl speakers as agents of this accelerated language change which leads to individual attrition and shift at the community level. This kind of multidisciplinary approach, taking into account both historical and modern data, can also potentially be useful for other minority languages in the scenario of long-term contact with a dominant language.

\section{Nahuatl Language}

Nahuatl is an agglutinative, polysynthetic, head-marking Uto-Aztecan language. As documented in its 'Classical' or sixteenth-century form, it employs compounding and incorporation, as well as derivation through the extensive use of suffixes and some prefixes. Its lexical categories can be divided into four basic structural classes: verbs, nouns, relational words (expressing spatial and other relations) and particles. In the early-colonial version of the language nouns are either animate or inanimate classes, 
with the latter group usually not pluralizable, except for the use of numeral classifiers combined with the singular form of inanimate nouns. Nominal morphology is based on both prefixing and suffixing and any noun can function as a standalone predicate. Verbs inflect with suffixes for tense, aspect and number, and with prefixes for the subject, the object(s) and direction of the action. Noun compounding, verb incorporation and derivation are extremely productive in colonial Nahuatl and facilitate the creation of new words. Three basic sentence types include a nominal predicate, an intransitive sentence, and a transitive sentence. At the syntactic level, colonial Nahuat can be classified as a non-configurational language, with a verb-initial basic word order that can be modified to encode pragmatic functions such as focus and topicality.

Nahuatl has had a long trajectory in Mexico, going back at least to the first millennium A.D. It was likely one of the languages spoken in the influential empire of Teotihuacan and, after its demise, in the Toltec state. In the last centuries before European contact, Nahuatl was spoken in numerous Central Mexican communities and polities. Finally, drawing on its already established status as a lingua franca in many regions of Mesoamerica, it flourished as the dominant language of the Aztec empire. After the arrival of the Spaniards, it was the first language learned by the friars who soon realized that they could use it to communicate with both Nahua and non-Nahua groups. Therefore the most extensive corpus of Mesoamerican ecclesiastical texts was created in this language, with members of the Nahua elite becoming the first disciples, collaborators and aides of Franciscans, Dominicans, Augustinians, as well as civil officials of New Spain. These circumstances, as well as language, administrative and church policy, further contributed to the spread of Nahuatl during the colonial period. On the other hand, the quick adoption of alphabetic writing by native intellectuals, scribes and notaries, made Nahuatl the main written indigenous language on the American continent, with an enormous corpus of literary, historical, legal, religious, administrative, and private texts beginning in the 1540s and continuing at least into the 1820 s.

Little of the past prestige, roles and geographical extension of the language has survived to the present day. Although the Mexican National Institute of Statistics and Geography (Ref. 1) reports an official population of some 1,544,968 native speakers of Nahuatl, in the overwhelming majority of those Nahua communities that have maintained the language into the second half of the twentieth century, intergenerational language transmission has been drastically weakened or has broken down entirely over the last few decades. The historical and modern circumstances that have brought about this situation include a vast array of complex sociological, political, and cultural factors, both internal (strategies of survival and welfare, response to national and global trends, attitudes toward cultural heritage) and external (national policies, racist attitudes, discrimination, the educational system). In this paper, I will bring to bear an extensive corpus of historical and ethnolinguistic data associated with colonial Nahuatl (Glottocode: clas1250; Ref. 2) and present-day speech communities in both strongly urbanized (Puebla-Tlaxcala, cent2132) and more peripheral rural communities (Huastecan region in northern Veracruz, east2538), in order to propose the following argument. Essential aspects of the process of language endangerment in some of the variants Nahuatl can be directly linked not only to 
gradually increasing external pressures affecting indigenous communities, but also to profound and accelerated contact-induced change occurring after centuries of contact with a dominant language as well as to the levels of speakers' proficiency.

\section{Unbalanced Language Contact and Language Shift}

I propose to view the Spanish impact on Nahuatl both in full historical trajectory and modern synchronic dimension in strict relationship to two types of contact: 'balanced', long-term language contact documented in historical sources and 'unbalanced' contact leading to rapid language abandonment in contemporary indigenous communities. The differentiation I propose closely relates to the notion of balanced versus displacive language contact (Ref. 3, p. 43-44), where the main criteria are mutual versus one-way bi/multilingualism and dominant position of at least one of the languages. However, I extend the notion of 'balanced' contact also to those situations involving a dominant language (with different kinds and extent of power relationships), which, generally speaking, do not pose threat to the continuity of a local language or local multilingualism. Balanced and unbalanced contact scenarios are often not clearly cut and dynamic: certain displacive tendencies may develop in balanced situations and then get reversed or expanded (Ref. 3, p. 44). This is the case of Nahuatl and this process has not been similarly paced or not uniform in all the communities, because some of them, especially in large, urbanized contexts with increasingly dominant Spanish and mestizo populations, were already exposed to unbalanced contact and its consequences in the colonial period.

In her studies on language obsolescence and death, Dorian (Ref. 4, p. 51; Ref. 5, p. 74-75) proposed the term language 'tip', referring to the situation of accumulated and accelerated rise of negative attitudes toward a language, including pressures from outside, leading to the moment of its abandonment and shift to a dominant language. Although the process may appear sudden, it is in fact often preceded by prolonged pressure on the language from inside and outside the community. Based on the combination of historical and contemporary sets of data, I argue that this is the case with regard to Nahuatl and Nahua culture. Some indigenous communities in large urban settings with increasing mestizo populations had already shifted to the dominant language toward the end of the colonial period and in the nineteenth century, while many rural communities followed in the twentieth century. In communities where Nahuatl has survived to the present day (such as those in Tlaxcala), the beginning of the process of language death can be traced back at least several decades; in others (such as the eastern Huasteca in Veracruz or Sierra Negra in Puebla), it is just incipient, although it shares certain characteristic processes that were already in operation in more urbanized areas several decades ago.

\section{Approach and goals}

While Dorian ${ }^{5}$ pinpoints this process in the patterns of use of the language in specific families, I would like to consider the combination of mutually interdependent and influencing variables. They include long-term extralinguistic factors with a 
cumulative effect, a purely linguistic dimension linked to contact-induced diachronic change, synchronic variation linked to speakers' proficiency but influencing language transmission in the diachronic perspective as well as sociolinguistic factors. Essential for studying the entirety of these processes is 'the articulation between the structure that dying languages may take and the use that is made of such languages' (Ref. 6, p. 180), influenced in multiple ways by changing cultural, social, political and economic circumstances. In this approach, I also draw on the methodological and theoretical proposal outlined by Sasse (Ref. 7, p. 10-12) and embrace extralinguistic, sociolinguistic and linguistic settings. Rather than limiting my study to the present configurations of factors affecting directly contemporary language communities, however, I view them in a strict relationship to their historical trajectories and conditions.

Summing up, the diachronic perspective is understood here as the totality of extra-, socio-, and intra-linguistic processes affecting the patterns of usage and transmission of Nahuatl as well as its lexicon, morphology, phonology and syntax over the last five centuries. The synchronic dimension refers to both inter- and intra-community variation: I propose to view variation between modern Nahuatl communities not only as the result of dialectological differences and their historical trajectories, but also differing states of intergenerational transmission and levels of acquisition of the language. The latter have become the driving force behind accelerated language change and attrition today. Language proficiency is also an important factor in synchronic variation within particular speech communities.

The point of departure for the research presented here is a multidisciplinary study focusing on cross-cultural transfer affecting Nahua language and culture over the last five centuries (Ref. 8). Over the years, it has turned into more holistically-oriented research on an endangered language embedded in its historical and modern cultural and social setting, combined with practically oriented, long-term actions aimed at its reinforcement and revitalization. Such a study requires a considerable variety of data and research methods. I rely on the ethnohistorical approach in accordance with the concepts and methods developed by the school of New Philology (Ref. 9), focusing on the reconstruction of colonial social, cultural, political, linguistic and economic history, primarily through indigenous sources written in native language and giving importance to both micro- and macro-patterns. This is supplemented by perspectives based on sources related to dominant culture that directly influenced indigenous communities and self-reflective ethnolinguistic, anthropological and sociolinguistic field research in modern communities as well as analytic methods of contact linguistics. Finally, I situate my work within the 'engaged humanities', an approach inspired by the notions and methods of Participatory Action Research (PAR) as well as Community-Based Participatory Research (CBPR), seeking efficient and nonpatronizing ways to not only actively involve community members in research projects and bring the results back to them, but also work out possible solutions for supporting heritage languages collaboratively. Part of this approach is to reflect on how research can contribute to developing practical solutions for preserving linguistic and cultural heritage. While I have already described proposed revitalization 
strategies elsewhere (Refs. 10-12) here I would like to link the alarming diagnosis of the current situation of Nahuatl and its speakers to necessary steps for the survival of the language. I hope the multidisciplinary approach I propose can also potentially be useful for other endangered minority languages that share the scenario of long-term contact with a dominant language.

\section{From Colonial to Modern Nahuatl: Extralinguistic Background}

The influential status that Nahuatl enjoyed in the diverse pre-Hispanic Mesoamerican linguistic landscape was maintained, despite intense colonization and Christianization, long into the colonial period in many key elements and structures of pre-conquest socio-political and economic organization as well as material and spiritual culture. This continuity, often in the guise of Spanish forms, was possible because the Nahua easily adjusted the new into their traditional patterns or reinterpreted it according to their own concepts, while Spaniards, often relying on indigenous ways of organization and local elites, were rarely aware of resulting discrepancies or transformation of the original peninsular models. The Nahua were able to preserve much of the structure and functions of the pre-conquest indigenous state, the altepetl, which usually became identified with the Spanish cabecera, or head town, while its elites and specialized notaries, as early as around 1540, started to use alphabetic writing for their own purposes, both linked to the legal and economic procedures of the colonial system and in order to preserve their own tradition and create various kinds of records. Numerous indigenous intellectuals faced the challenge of exploring different aspects of European culture and literary genres: translated, related and reinterpreted in Nahuatl biblical and hagiographic stories, devotional materials, travelers' accounts, references to Classical antiquity, or theatrical works.

Toward the end of the colonial period indigenous elites became almost entirely Hispanicized and writing in Nahuatl became limited mainly to mundane genres (such as wills) and local land titles. Nonetheless, during much of the colonial period the Nahua were able to use Nahuatl in their socio-political life and its institutions, in the court and in the religious sphere. In 1550, King Charles I of Spain, concerned that a native language would not be fully capable of conveying Christian doctrine, ordered that all indigenous subjects of the Spanish crown be provided with the means to learn the Castilian language. However, in the reality of Christianization and administration, the reliance on Nahuatl, also in dealings with other ethnic groups, became a practical necessity and a much more efficient solution, while ecclesiastical regulations favored priests with knowledge of a native language (Ref. 13, p. 676-687). Responding to this situation, Phillip II decreed in 1570 that Nahuatl serve as a universal language for all natives, obliging ecclesiastics to learn it. As the colonial period progressed, the crown's policy became less open to the use of indigenous languages and in 1634 Philip IV issued a decree obliging the clergy to teach the indigenous population in Spanish, while in 1693, on order of the viceroy, schools for Spanish language instruction were to be established in all provinces of New Spain, and 
especially in indigenous towns. This policy was further supported by the Fourth Provincial Council of Mexico in 1771 (Ref. 14, p. 692-693).

However, despite these efforts, by the end of the colonial period only some $35 \%$ of the population spoke Spanish (Ref. 15, p. 360). Available indigenous and Spanish sources imply that in the early and mid-colonial period bilingualism in Nahuatlspeaking communities was minimal, probably limited to representatives of elites, some officials and translators. In the colonial period bilingualism among the indigenous population was certainly developing much faster in large towns with considerable Spanish and mestizo populations, such as Mexico-Tenochtitlan, Cuernavaca, Zacatecas or Toluca, and these large metropolises with mixed populations witnessed the shift to Spanish most rapidly, probably already toward the end of the colonial period and into the nineteenth century. On the other hand, in the sixteenth and seventeenth centuries Nahuatl was quite often used as part of vernacular culture by members of other ethnic groups and by Spaniards interacting with indigenous populations (Ref. 16, p. 747). It is significant that, as late as the second half of the eighteenth century, Nahuatl was used to write legal documents in the predominantly Otomi town of Ixtenco, which implies it was spoken as a second language and used as a prestigious written language (Ref. 17), which may well have been the case in other towns, too. After 1821 the language policy of the newly independent Mexican state, in fact, laid the ground for the era of strong linguistic homogenization of the twentieth century: it is significant that, according to the first census of 1895, as much as $83 \%$ of the population spoke Spanish, while only $16.6 \%$ declared themselves to be speakers of indigenous languages. This tendency toward substitutive bilingualism was further accelerated by the language policy of the twentieth century, strongly based on the promotion of 'bilingual education', accompanied by many forms of physical and psychological violence, which was, in fact, the direct method of shifting the indigenous population to Spanish (Ref. 15, p. 361-363).

Other essential factors, apart from state policy, that strongly affected biological and cultural survival, sustainability and self-determination of indigenous communities include recurring waves of epidemics throughout the sixteenth and early seventeenth centuries, which drastically reduced the native populations that lacked immunity to European diseases, as well as many forms of economic exploitation under colonial system. Furthermore, the impact of urbanization and pressure on indigenous land played an important role; the struggle for land intensified in the eighteenth century in view of demographic growth and increasing non-indigenous settlement, while the economic policies of the Mexican state toward indigenous land-holding further undermined the traditional economy and sustainability of native communities.

\section{Contact and Language Change: A Historical Outline}

Nahuatl and other native languages were exposed to the Spanish language and culture from the first decades of contact and we are able to trace this long-term contact-induced change thanks to the enormous corpus of indigenous texts. Lockhart (Ref. 18) performed the only comprehensive study of the evolution of colonial 
Nahuatl under Spanish influence. His research divided the process into three stages. In Stage 1 (1519-1540/1550), Nahuatl remained almost unaffected: the new phenomena, objects and concepts were described by means of neologisms and extensions of meaning. In the next stage, lasting approximately to the mid-seventeenth century, the language underwent little change at the level of morphology, syntax and phonology, despite the widespread borrowing of Spanish nouns and coinage of calques. In Stage 3, which according to Lockhart began around the mid-seventeenth century and continues until now in those communities where Nahuatl is still spoken, change has been deeper and marked by the borrowing of verbs and particles, the adoption into Nahuatl of plural forms for inanimate nouns (traditionally unpluralized) and of Spanish phonemes, as well as an increasing presence of lexico-syntactic calques. Certainly, direct language interaction must have been stronger in the later part of the colonial period as bilingual persons started to have a greater impact on language change. However, it seems little justified to extend the colonial phase to the modern stage of language change because, as I will argue below, it includes entirely different categories of change, markedly distinct from those seen toward the end of the colonial period. They are characterized by heavy convergence with Spanish at all levels of the language structure, accelerated typological change and massive, substitutive borrowing from Spanish.

Regarding colonial language change, the analysis of a large sample of texts from different regions reveals that the pace and extent of language change differ depending on the degree of exposure to cross-cultural contact, urbanization, and the strength of local indigenous organization. Change is more rapid in the northern and southern periphery (Ref. 19) and indeed these areas witnessed a shift to Spanish much earlier than central Mexican communities. Moreover, not only timing, but also some characteristics of stages are more complex. Spanish loanwords are already attested in the earliest surviving texts in Nahuatl, dating to the early 1540s, which implies a necessity to reevaluate the nature of the first phase of contact. Neologisms continued to be produced throughout the colonial era and down to the present, though with decreasing frequency. Loanwords were limited to names of objects or concepts lacking in Nahuatl and were subject to the full range of phonological adaptation and morphological derivational processes operating in Nahuatl; even if an already existing term was borrowed, such as Spanish enemigo 'enemy', it was adopted with a different meaning, in this case referring to Englishmen and heretics.

While the clear majority of the indigenous population lacked direct knowledge of Spanish, it is possible that the source of innovations was individual bilingual speakers who played important roles in indigenous communities or as mediators between the two cultures. These could be notaries, municipal officials or indigenous intellectuals such as the prolific Nahuatl writer, don Domingo de San Antón Muñón Chimalpahin Cuauhtlehuanitzin, an annalist living in Mexico-Tenochtitlan at the turn of the sixteenth and seventeenth centuries. He employs an enormous amount of both Spanish loanwords and Nahuatl neologisms (many of which he appears to have coined himself) that surely were not in use to the same extent among the actual speakers in communities outside the metropolis. His language use also predates contact-induced phenomena attested later in mundane community texts, such as the adoption of certain Spanish kinship terms, such as primo hermano (Ref. 20, p. 48-49). 
However, they were not meant to replace, but rather enrich the native classificatory system of kinship terms.

Some of these replicated patterns triggered a morphosyntactic typological change, salient in modern Nahuatl, but whose origins are traceable already in the colonial period. Thus, the diachronic perspective reveals how some key lexical borrowings of the colonial period gradually began to replicate more and more Spanish syntactic patterns. A good example is the Spanish preposition para 'for', initially borrowed with this most basic meaning:

(1) [1653 Petition of the town of San Martin, Guadalajara, McAfee Collection 20:9]

Çacatl

zaca-tl

grass-ABS.SG

'grass for his horse' ycabalyo

i-caballo(h)

POSS.3SG-horse

Eventually, the use of para triggered the replication of other syntactic functions of Spanish as shown by an eighteenth-century document from Toluca, in which it is used as a conjunction introducing a dependent clause:

(2) [1750, a legal statement, Calimaya, Toluca Valley, AGN, Tierras 2541, exp. 11;]

\begin{tabular}{|c|c|c|c|c|}
\hline quenc & & mitlan & & se \\
\hline quen & & $\varnothing-\mathrm{m}-\mathrm{i}$ & lania & ce \\
\hline how & & SBJ.3s & REFL.3SG-request & ne \\
\hline tlali & & para & campa & luitu \\
\hline al-li & & para & cam-pa & $-\mathrm{c}$ \\
\hline nd- &.$S G$ & for & where-toward[RTL] & SB \\
\hline ne & yey & grar & tloli & \\
\hline ne & yeyi & gra1 & tl(a)ol-li & \\
\hline & three & grai & shelled_corn & \\
\hline
\end{tabular}

'that a piece of land is requested (for) where he is to plant two or three grains of maize'

Such functions became widespread in modern Nahuatl, where para is used in indirect speech replicating the Spanish que 'to' and para que 'in order to'. This has had a deep impact on traditional Nahuatl syntax which reported speech directly:

(3) [2012, Tepoxteco, Chicontepec, Veracruz]

$\begin{array}{llll}\text { Quiillia } & \text { para } & \text { quena } & \text { caxaniz. } \\ \text { Ø-qui-illia } & \text { para } & \text { quena } & \text { Ø-caxani-z } \\ \text { SBJ.3SG-OBJ.3SG-tell } & \text { that } & \text { yes } & \text { SBJ.3SG-loosen-FUT }\end{array}$

'He tells him that she will indeed recover.'

Thus, the Spanish loanword para functioned in Nahuatl at various levels of linguistic structure, first as a lexical calque and preposition at phrase level and then increasingly as a conjunction and relative pronoun at clause level. The effect of the borrowing of para and other Spanish conjunctions is eventually visible at the 
syntactic level, calquing Spanish patterns by introducing new kinds of purpose clauses and increasing the differentiation between coordinate and subordinate clauses (cf. Ref. 21, p. 137). By doing so, this loanword ultimately modified the syntactic structure of Nahuatl as a carrier of typological change that became the driving mechanism of an accelerated transformation of modern varieties of the language.

\section{The Synchronic Context: Modern Nahua Communities}

Today Nahuatl is still spoken in several states in both urbanized and rural settings. With few exceptions, it is only in the most secluded peripheral communities that the language is still transmitted to children. My study is based on data both from communities undergoing a rapid shift to Spanish (Tlaxcala, Estado de Mexico) and those where the language is still spoken by all generations, but bilingualism is common and Spanish usurps more and more domains of use (Chicontepec region in the Huasteca Veracruzana, Sierra Negra and Zoyatla in Puebla). There are some important differences between those communities, both in terms of language use and the conservation of traditional culture.

In rural communities in the Huasteca, many core elements of traditional religion, beliefs and rituals have survived to the present day, peacefully coexisting with certain Christian practices. Communities retain more features of traditional economy (agriculture) and have been generally less exposed to communication with the outside world. In the entire municipality of Chicontepec out of the total population of 52,702 persons, 37,000 inhabitants (ca. 70\%) declared themselves to be speakers of indigenous languages, mainly Nahuatl (Ref. 1); only 3,051, mainly the eldest generation, did not speak Spanish, being largely monolingual in Nahuatl. Proportions are different with the youngest age groups signaling the decrease of intergenerational transmission: within the total 12,708 of children between the ages 3 and 14 only 6,499 (ca. $51 \%$ ) was reported or declared to speak an indigenous language, while only 86 $(0.68 \%)$ of them do not speak Spanish. Children are increasingly exposed to Spanish throughout their entire school education. In the rural town of Tepoxteco, from which comes most of the analyzed data, there is a population of approximately 400 inhabitants; the language transmission is maintained in most of the families, but in some families an emerging pattern of transmission is between grandparents and grandchildren, with the generation of parents tending to speak Spanish. In contrast, in Tlaxcalan communities, traditional agriculture is maintained only so as to provide additional support to wage labor and local industries (such as textile production) and other businesses.

In terms of the sociolinguistic situation, the Tlaxcalan municipal localities are currently facing an imminent threat of language extinction, with rapidly diminishing intergenerational language transmission, a growing number of passive speakers, drastically shrinking domains of use, and differing language competence among members of the speech community. Of the total population of the municipality of Contla de San Juan Cuamatzin (Ref. 1) of 33,109, 5,124 (ca. 15.5\%) speak Nahuatl and only 14 of them have been identified as monolingual in Nahuatl; of the total of 
8,477 children between the ages 3 and 14 , only 250 (ca. $2.9 \%$ ), speak Nahuatl, all of them bilingual. There are no monolingual Nahuatl speakers left (but some of today's elderly speakers did not learn Spanish until their forties).

Very few children and teenagers are able to speak the language. Outside their communities of origin migrants typically abandon or drastically restrict the use of Nahuatl and cease to transmit it to their children. Most Nahuatl-speaking communities lack bilingual schools, not to mention immersion education in the native language, and children receive all education in Spanish; for the last several decades parents were strongly encouraged to communicate with their children in Spanish to save them problems at school and in later life, which heavily contributed to language shift in Tlaxcala (Ref. 22, p. 112-113). The presence of bilingual schools is not of much help, because instruction is carried out almost exclusively in Spanish, with the school functioning as an efficient tool for transitioning native children to Spanish (Ref. 23, p. 40-42). The shift to Spanish is also spurred on by the progressing disintegration of traditional economy and production modes based on agriculture and local manufacture specialization as well as by the hugescale migration to large Mexican towns and the USA, with migrants rarely continuing to use the heritage language. Other key factors include low prestige of Nahuatl associated with external pressure, racist attitudes, lack of literacy in this language, lack of opportunities for using the language in municipal offices or medical clinics (with few recent exceptions, e.g. in Tlaxcala where translators were hired for local hospitals), weak historical identity, and lack of knowledge of, and a sense of relating to the Aztec/Nahua past and heritage, including the colonial writing tradition. A denial, propagated by the Mexican academy and cultural institutions, of any direct connection between modern variants of Nahuatl and the 'language of the Aztecs', has likewise contributed to a widespread negative perception of the current 'dialects' as degenerated and illegitimate mixtures of an earlier authentic Nahuatl and Spanish, which is sometimes strengthened by purist attitudes that stigmatize the Hispanicized speech of most community members (e.g. Ref. 23, p. 122-123; Ref. 24).

\section{Unbalanced Contact Today: Accelerated Language Change}

The vitality and degree of endangerment of Nahuatl depends on each specific community/region (the basic criterion being the presence or lack of intergenerational transmission); it should not be currently viewed as an obsolescing language in all of them. However, in many communities in Tlaxcala and Estado de Mexico, as well as some in Puebla, where transmission is entirely or significantly broken, Nahuatl may cease to be used within one to two generations. Some changes in obsolescing languages are viewed as 'natural', with the exception of the rate of change, which is particularly accelerated in comparison to languages in 'healthy' conditions (Ref. 25, p. 83; Ref. 26, p. 111). Nahuatl is in a situation of being strongly dominated by Spanish, and this unbalanced power relationship has been steadily increasing since the colonial era, along with many forms of external and internal pressures (linked to local socio-political and economic circumstances as well as to strategies of specific communities). I argue that, in the case of those communities that did not undergo the 
shift to Spanish, prolonged language contact across the colonial period and, in some parts of independent Mexico in the nineteenth and twentieth century, remained within 'balanced' parameters. Thus, contact-induced change did not pose a threat to linguistic and cultural continuity, in terms of its functional coverage of the whole scope of domains and speakers' proficiency because neither the spaces of use nor language transmission were threatened by the functions and the prestige linked to the dominant language. An exception to this scenario, at least in the chronological dimension, are communities such as those in the Valley of Mexico, large towns and the northern periphery, all of which abandoned Nahuatl somewhere between the later part of the colonial period and the first half of the twentieth century; however, we lack language documentation addressing the characteristics of this process.

Although a number of features typical for the current state of language change are shared by all modern variants of Nahuatl, I focus here only on those aspects that are most indicative of accelerated change and the kinds of phenomena described by linguists as 'decay', correlated with 'a phase of gradual death', occurring in an ongoing shift from a minority language to a dominant language in a situation of unstable multilingualism and usually directly linked to the interruption of complete language transmission (e.g. Ref. 7, p. 15; Ref. 27). The use of the term 'decay' is controversial because of the negative associations and low evaluation of the language that it triggers in the perception of its speakers, who may thus be further discouraged in their use of an endangered language. However, I think that it is necessary and helpful for any revitalization attempts to understand and define the linguistic symptoms and consequences of unbalanced contact and change that contribute to language abandonment.

At the lexical level, the most salient feature of this phenomenon is massive lexical borrowing from Spanish; it is not always motivated by the lack of a specific term in Nahuatl, but tends to replace existing vocabulary. This includes the use of loanwords for all new concepts and objects at the expense of neologisms. In contrast to earlier stages of contact, these loanwords are rarely adapted phonologically and rarely undergo morphological derivation. Although it is extremely difficult to pinpoint the 'critical mass' of substitutive borrowing linked to language obsolescence, it is significant that speakers are no longer solving problems of expression or wording through word formation/creation, but rather through borrowing, code mixing and code switching. Thus, new words are no longer created, and consequently, the language loses its internal productivity. Speakers' reactions to neologisms created according to the rules of Nahuatl word formation are characterized by a lack of understanding, surprise, distrust or even amusement. This phenomenon, eliminating internal lexical enrichment, is considered an early sign of 'decay' (Ref. 27). It is accompanied by a gradual reduction or loss of morphological derivation (e.g. creation of agentives, patentive nouns, etc.). Substitutive borrowings at the level of conjunctions influence the syntactic structure, as in the following utterance of a teenage speaker from a community in Puebla who learned and used the language at home but was exposed to an education entirely in Spanish (example (4); Spanish loanwords in bold). In this example, a common Nahuatl verb piya, which since the 
end of the sixteenth century has functioned as a calque of tener 'to have', is replaced by teneroa, a verbalized loanword:

(4) [2014, Zoyatla, Puebla]

\begin{tabular}{|c|c|c|c|c|c|c|}
\hline Amo & \multicolumn{3}{|l|}{ xicagarraro } & odio & $n i$ & renc \\
\hline Amo & \multicolumn{3}{|l|}{ xi-c-agarrar-o } & odio(h) & ni & \\
\hline no & \multicolumn{3}{|c|}{ SBJ.2SG.OPT-OBJ.3SG-grab-VR } & hatred & nor & \\
\hline \multicolumn{2}{|c|}{ xiquillamiqui } & que & yehhua & $a$ & lo & mejo \\
\hline \multicolumn{2}{|c|}{ xi-qu-illamiqui } & que & yehhua & $\mathrm{a}$ & lo & mejor \\
\hline \multicolumn{2}{|c|}{$\begin{array}{l}\text { SBJ.2SG.OPT-OBJ.3SG- } \\
\text { remember }\end{array}$} & that & PPN.3SG & perl & & \\
\hline
\end{tabular}

\begin{tabular}{|c|c|c|c|c|c|}
\hline amo & quiteneroa & $o$ & quiignoraroa & ciertas & cosas \\
\hline am & $\varnothing$-qui-tener-oa & o & $\varnothing$-qui-ignorar-oa & cierta-s & cosa-s \\
\hline no & SBJ.3SG-OBJ.3SG-have-VR & or & $\begin{array}{c}\text { SBJ.3SG-OBJ.3SG- } \\
\text { unaware_of-VR }\end{array}$ & certain-PL & thing-PL \\
\hline
\end{tabular}

'Do not enter into hatred or resentment. Remember that this person perhaps does not have or is ignorant of certain things.'

In addition, we can see important innovations at the syntactic level. Que (Sp. 'that') modifies the original syntax, as do the Spanish conjunctions ni 'nor' and $o$ 'or', which replace Nahuatl particles. Que is currently used as a subordinating particle, whereas in colonial Nahuatl clauses were often juxtaposed rather than formed by subordinators/conjunctors (cf. Ref. 21, p. 104). The most common subordinator in older Nahuatl was the particle in as well as some relational words; however, subordinate sentences like the one above (4) that are now constructed with que, would traditionally be rendered as direct speech.

Lexico-syntactic calques are another common source of typological change from a polysynthetic to a more analytic language, and they lead to morphosyntactic innovations. Thus, a traditional way of saying 'we make a feast for our deities' would be with the use of the benefactive:

(5) [traditional Central Nahuatl]

Tiquinilhuichihuiliah

ti-quin-ilhui-chihui-lia-h

SBJ.1PL-OBJ.3PL-feast-make-BEN-PL

'We make a feast for our deities.' totiotzitzin

to-tio-tzin

POSS.1PL-deity-small[REV]

A common modification in contemporary Tlaxcalan Nahuatl would be the use of para instead of the benefactive:

(6) [modern Central/Tlaxcalan Nahuatl]

$\begin{array}{lccc}\text { Ticchihuah } & \text { ce } & \text { fiesta para } & \text { totiotzitzin } \\ \text { ti-c-chihua-h } & \text { ce fiesta para } & \text { to-tio-tzi-tzin } \\ \text { SBJ.1PL-OBJ.3SG-make-PL } & \text { one/a feast for[PREP] } & \text { POSS.1PL-diety-FREQ } \text { small } \\ \text { 'We make a feast for our deities.' } & \text { [REV] }\end{array}$


Yet another possibility is given in (7): a speaker in his late fifties from San Miguel Xaltipan, Tlaxcala, who was no longer using Nahuatl regularly in everyday interactions, mimicked the Spanish pattern of using hay 'there is/are' and replaced the traditional 3rd-person possessive pronoun prefixed to a possessed noun with de, a Spanish preposition:

(7) [2014, San Miguel Xaltipan, Tlaxcala]

cateh feztividadez de totiotzitzin

$\varnothing$-cat-e-h feztividade-z de to-tio-tzi-tzin

SBJ.3PL-be-NPRES-PL celebration-PL of POSS.1PL-diety-FREQ small[REV]

de tozantoz

de to-zanto-z

of $\quad$ POSS.1PL-saint-PL

'There are celebrations for (related to) our deities, our saints.'

The increasing incorporation of de into Nahuatl has a very strong effect on the language structure: it has drastically reduced and with many speakers entirely replaced, nominal compounding and head-marking in possessive noun phrases. Thus, instead of saying María ical (María i-cal; Maria POSS.3SG-house) for 'Maria's house', a common way to say the phase today would be calli de María (house of [PREP] Maria); for compound nouns, cuauhcalli (cuauh-calli; wood-house) would be replaced by calli de cuahuitl (house-ABS.SG of[PREP] wood-ABS.SG). Similarly, in traditional Nahuatl the verb is usually the head of a clause, and all subject and object relations are marked on it. This form of head-marking becomes reduced at the expense of prepositions and no-marking $(7,10)$. Typological change is also caused by frequent instances of pattern replication (Ref. 28) that include, for example, the calque of the past progressive from Spanish:

(8) [2014, Coxcatlan, Puebla]

tlamiyah

Ø-tlami-ya-h

SBJ.3PL-finish-IMPF-PL oncatcah

Ø-on-cat-ca-h

SBJ.3PL-OUTDIR-be-NPRES-PL

'They were finishing.' (Sp. 'estaban terminando')

The construction in (6) is commonly used instead of the traditional imperfective or progressive aspects based on auxiliary verbs:

(9) [traditional Nahuatl]

otlanticatcah

o-Ø-tlan-ti-cat-ca-h

ANTEC-SBJ.3PL-finish-LIG-be-NPRES-PL

'They were finishing.'

The above examples illustrate ways of compensating for disappearing forms. Other phenomena linked to typological change include reduction or total 
disappearance of relational words (converted into the new lexical category of prepositions, modeled on Spanish), traditional possession, the benefactive, noun compounding and incorporation, and reduction of complex syntactic agglutinative structures. Such system-altering changes, which include the acquisition, on the part of the head-marking polysynthetic language, of more dependent-marking or nomarking properties and a more analytic profile in general, are typical for unilateral convergence in the conditions of unbalanced contact and relations of dominance (cf. Ref. 29, p. 32-33).

All of these changes are compensated for by the use of more analytic constructions that employ Spanish prepositions such as de and para. Some reductions however, are not compensated for. Examples include the disappearance of the categories of animacy and numeral classifiers (the adoption of Spanish pluralization for all nouns involves semantic reduction); the loss of reduplication (implying repetitive, intensified or distributive action in time and space); the disappearance of honorific forms (reverential verbal constructions, honorific nouns, closely linked to stylistic shrinkage) and of the causative (unlike the benefactive, it is not so easily compensated for by Spanish descriptive constructions because such constructions are not very common in Spanish). The latter examples correspond to 'dysfunctional changes' as defined by Dressler (Ref. 27). Recurring among the speakers of most endangered variants is the disappearance of grammatical rules and the use of ungrammatical constructions, such as the lack of personal pronouns on predicates. Thus, a speaker from Tlaxcala who learned the language as a teenager optionally omits the traditionally obligatory specific object prefix qui-:

(10) [2015, Tlaxcala, attestation]

amo chihuah miac

amo $\varnothing$-chihua-h miac

no SBJ.3PL-do-PL much

'they do not do much'
Traditional Nahuatl (older and modern) amo quichihuah miac amo Ø-qui-chihua-h miac no SBJ.3PL-OBJ.3SG-do-PL much

Such changes become dysfunctional because the indication of person or number remain uncompensated. An almost fluent speaker from Tepoxteco (Chicontepec, Veracruz) who did not learn the language at home but from casual contact with speakers in the community, often preserves the absolutive suffix in possessive constructions modeling the pattern of Spanish where possessed nouns only take a possessive prefix:

(11) [2016, Tepoxteco, Veracruz]

Quitepehua
$\varnothing$-qui-tepehua

SBJ.3SG-OBJ.3SG-throw_out

itlazolli

i-tlazol-li

POSS.3SG-trash-ABS.SG [for itlazol]

[for i-tlazol]

[for POSS.3SG-trash]

'He is throwing out his trash.'

At the phonological level, non-fluent or rusty speakers in Tlaxcala often omit the final glottal fricative used as a plural verbal marker or fail to distinguish between long and short vowels, which has implications for the correct differentiation between distinct 
morphemes. Common features are the lack of awareness of grammatical categories and the use of ungrammatical constructions. In the following example, the speaker gives the plural form of a verb in the present tense the function of a noun, modelled on a construction from Spanish:

(12) [2014, San Miguel Xaltipan, Tlaxcala]

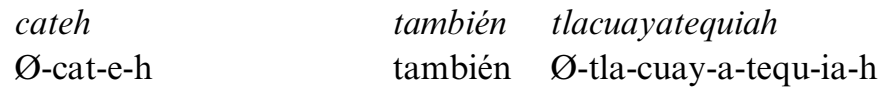

SBJ.3PL-be-NPRES-PL also SBJ.3PL-OBJ.NHUM-head-water-pour-BEN-PL 'There are also baptisms [lit. 'there are also they baptize'] /también hay bautizos'.

On the other hand, the relative degree of language change and patterns of use vary considerably, not only between regions, but also within a single (usually entirely or predominantly bilingual) community. This local differentiation is doubtlessly linked to distinct degrees of language proficiency and profiles of speakers. Under these conditions, many rules become optional, while code mixing and code switching are an unmarked norm.

\section{Language attitudes}

There is little, if any, institutional support for Nahuatl. Negative language attitudes are common, but at least in Tlaxcala there seems to have been a slight improvement in language attitudes, in contrast to the sociolinguistic situation documented thirty years ago by Hill and Hill (Ref. 22). This change is reflected in the fact that, according to our recent fieldwork, roughly half the speakers consider Nahuatl to be an autonomous language and only 37\% a 'dialect,' (a much less prestigious or even pejorative category) which signals a significant rise in its recognition as a 'language'. However, in a similar query in Sierra Negra, where the transmission is still in operation, the majority of respondents $(76 \%)$ consider Nahuatl to be a dialect, even if most of them have trouble explaining what a dialect is (Ref. 30, p. 321, 325-326). A clear majority (75\%) of community members interviewed in Tlaxcala also declared that it is important to learn Nahuatl, while $93 \%$ of non-speakers and passive speakers affirmed they would attend Nahuatl classes in their communities if they were offered. A strong majority (up to $100 \%$ in Sierra Negra) consider literacy in their heritage language desirable and necessary (Ref. 30, p. 323, 327). Almost all the indigenous participants, from all age groups, who worked with us in different workshops, declared that their main purpose in participating was to learn how to write the language.

However, these declared positive attitudes are generally not reflected in language transmission and learning. The status of the language is also viewed in close relationship to language change and the impact of Spanish. In Sierra Negra (71\%) most of the speakers perceive this influence in an overtly negative way, and consider that, because of mixing, they no longer speak Nahuatl. However, in Tlaxcala, where language transmission is mostly broken and where code mixing and switching is widespread, $29 \%$ of the participants affirmed that using Spanish vocabulary is 
positive because it allows less fluent speakers to understand Nahuatl, while only $23 \%$ have a negative outlook on this process (Ref. 30, p. 322, 326-327). This situation seems to be linked to the fact that the number of non-fluent native speakers in this region has been rapidly growing and mixing/switching has become a socially acceptable norm accompanied by its diminishing awareness, even if the oldest speakers criticize imperfect younger speakers. At the same time, however, many persons are aware, and sometimes ashamed, of their lack of language proficiency and reveal insecurity in speaking. Many report having difficulty expressing certain ideas in Nahuatl, especially in the areas not linked to household/family/traditional activities, such as politics, social life, internet, or the economy.

\section{Toward a typology of speakers}

For these reasons, I consider the role of imperfect speakers ('semi-speakers,' 'rusty speakers,' 'rememberers', 'pseudo-/quasi-speakers'; Refs. 4-7; Ref. 22, p. 49, 80) to be one of the major driving forces of the endangerment and abandonment of Nahuatl today, especially in the areas that witness the interruption of language transmission. Even in the communities where language is still spoken by the majority, it is not uncommon to find families in which the grandparent and parent generations are fully proficient, the oldest, usually teenager or adolescent children can speak with differing levels of proficiency, their younger siblings are passive speakers, while the youngest are non-speakers (e.g. families in San Miguel Tenango/Zacatlan, Sierra Negra), which evokes the situation of Gaelic-speaking families as described by Dorian (Ref. 5 , p. 76). For the purposes of a general description of a broad continuum of speakers' proficiency, I propose a working typology with blurred boundaries (having no intention of 'labelling' individual speakers or reflecting the potential dynamics of their language competence and use).

1. Fully proficient speakers who are scholars, students, writers or activists, conscious users of the language; they have full language capacity in any domain; some of them reveal purist attitudes towards the language and avoid loanwords and code mixing.

2. Fully fluent speakers from traditional communities with unbroken transmission who either still use the language in their home community or have migrated, but continue speaking whenever back in the community. The use of language and adaptation skills to different domains varies, but generally the proficiency is very high. Depending on the region and community of origin, some of them resort to heavy codemixing, for example teenagers/young adults who learned the language and use it at home and among their peers, but received no school instruction in Nahuatl (and had exclusively Spanish instruction from the age of 6) and have not developed complex structures and vocabulary related to many domains of life.

3. Semi-fluent speakers who learned in increasingly bilingual homes, but whose use of language is limited to basic domains, confined vocabulary 
and reduced grammatical structures; some of them purposefully tend to omit loanwords and code mixing, but spontaneous speaking on a wider variety of topics requires considerable effort on their part. The borderline with semi-speakers is fluid; there is a continuum in terms of proficiency.

4. Semi-speakers with varying degrees of proficiency who acquired the language from their grandparents or other community members because parents, even if they spoke among themselves or knew the language, did not talk to them in Nahuatl. Language acquisition often took place at a later age, when they were teenagers or young adults. Many committed teachers, translators or activists belong to this group and learning the language was their conscious decision, but they are aware of their lack of full proficiency, often emphasizing the need to 'learn the language better'; they also often lack spaces for practicing and developing language skills.

5. 'Rusty'/terminal speakers who learned as children but have not been using the language regularly, for a long period of time or in many domains. They are typically members of communities with a broken language transmission and migrants. Their speech is characterized by heavy code-mixing and code-switching. They often exhibit difficulty in expressing themselves. Such speakers are frequently ashamed of their reduced language skills.

6. Passive speakers whose parents did not pass the language on to them; most of them refuse to speak the language, but those who decide to start speaking usually use a simplified and Spanish-influenced structure and a very basic vocabulary.

Massive substitutive borrowing and also frequent code-mixing (its scale depends on the community and region), is salient with most fluent speakers who did not develop language skills beyond the home environment. Substitutive borrowing and codemixing is much less frequent with 'fully proficient speakers' who are conscious users of the language. Other signs of accelerated language change, including functional dysfunctions and ungrammatical features are most salient in less fluent/semi-speakers (examples 10 and 11), rusty (example 12) and terminal speakers as well as passive speakers. In communities with broken or weakened intergenerational transmission, these speakers are source of internal synchronic variation. It is also significant that many semi-fluent, semi-speakers and even former passive speakers, decide to become committed teachers, both in bilingual schools and in informal teaching that they organize at their homes and other spaces for community children and youths who no longer can learn the language from their parents. They learned the language in incomplete ways, whereas the current attitudes at the family level, institutional support and available materials often do not allow them to fill the gaps, of which they are usually aware. Whereas their language usage bears the strong impact of 'imperfect' learning, the language skills of their students are inevitably influenced by 'imperfect' teaching. This kind of language transmission perpetuates many traits linked to reduced proficiency and synchronic variation among bilingual semi-speakers whose 
performance in the heritage language does not match that in the dominant language. Since in many communities the language is not passed on naturally anymore, the source of 'imperfect' teaching is often such speakers. As a teacher from Tlaxcala expressed it,

(13) Neh oniczaloh nin tlahtol ihcuac onicpiyaya mahtlac occe xihuitl huan oniczaloh inahuac nocihtzin. Notahtzin huan nonantzin amo nechittitihqueh tlica yehhuan oquihtoayah yocmo, yocmo sirve, nin tlahtol yocmo sirve.

'I learned this language when I was 11 years old. And I learned it from my grandmother. My father and my mother did not teach me because they were saying it is not useful any more, this language is not useful anymore.'

Another teacher from a community in Estado de Mexico, now in his 70s, declared:

(14) Huan axcan, axcan quena nicmati mati ye achi tepitzin ye oc achi cualli nictenquixtia nahualcopa, amo nochi nicmati quence miec tlahtolli, amo nicmati quen mittoz nahualcopa ca no zan ye cualli nitenohnotza huan axcan nitemachtihticah.

'And now, now yes I know a little, I can pronounce the Nahuatl language, I do not know everything, many words, for example, I do not know how something would be said in Nahuatl. [But] I can converse rather well and now I teach [Nahuatl].'

\section{What can be done? Conclusions and prospects}

On the basis of extensive fieldwork and linguistic documentation, I have identified various kinds of Nahuatl speakers as agents of accelerated language change leading to individual attrition and community shift. I illustrate this point by documenting specific reductional linguistic processes at the levels of lexicon, morphosyntax and phonology, with a focus on such phenomena as decreasing lexical richness and registers of use, substitutive massive borrowing, and code-mixing, disappearance of word-formation mechanisms, loosening of grammatical rules, and deep typological change. An indispensable contrastive sample for this analysis has been an extensive corpus of colonial documentation spanning several centuries as well as linguistic documentation of highly proficient speakers of the variants studied. I have also argued that unbalanced contact and accelerated language change, fostered by incomplete transmission or reduced spaces and contexts of use, translates into speech behaviors, attitudes, speakers' self-evaluation and psychological motivations. The historical and modern extralinguistic setting is tightly interwoven in this scenario, embracing cultural, social, political and economic processes, which together have shaped the modern situation in which there are many forms of pressure on specific communities to abandon their heritage language. Accumulated experiences of trauma, denied historical identity, inherited colonial relationships, discrimination, economic exploitation and disintegration of local economy all continue to build on the historical legacy of Nahua communities. The social norms and patterns of language use have been evolving too, in a close relationship to both language policies and the above-mentioned extralinguistic factors. The relationship of linguistic dominance has been developing too, perhaps never being so salient and strong as over the last several decades. These phenomena are closely linked to increasing synchronic 
(especially internal) variation, which now appears to be not so much driven by dialectal differences between communities and regions, but by the sociolinguistic profile of the communities, the state of transmission and proficiency of speakers. And all of these variables strongly contribute to structural change and ongoing shift.

Not all of these processes have to be irreversible, both in the case of Nahuatl and other endangered languages. It is still possible to come up with efficient strategies to counter and reverse widespread language shift and create spaces for the use of local languages in new economic and social circumstances (Refs. 10-12). In the face of dwindling proficiency in language use, professional teaching in as many spaces as possible, and creation of monolingual materials along with permanent spaces of language practice inside and outside the communities, are a basic and fundamental necessity. External/international support is crucial for such initiatives as well as for overcoming negative attitudes. Ethnohistorians, anthropologists, linguists and other professionals can play an important role both in providing language resources that have fallen out of use and in the process of recuperation of historical identity by modern indigenous people. They can do so by actively sharing knowledge about the past and present of native cultures and thus bridging the perceived gap between pre-conquest and modern times in favor of cultural continuity.

\section{Abbreviations}

ABS absolutive, ACNNR active action noun, AG agentive, ANTEC antecessive, BEN benefactive, CAUS causative, FREQ frequentative, FUT future, HABIT habitual, HUM human, IMPF imperfective, INDIR inbound directional, INST instrumentative, INTS intensification, LIG ligature, NACT non-active, NEG negative, NHUM non-human, NPRES non-present, NUM.CLF numeral classifier, OBJ object, OPT optative, OUTDIR outbound directional, OUTPURP outbound purposive, PATN patientive, PL plural, POss possessive, PPN personal pronoun, PREP preposition, REFL reflexive, REV reverential, RTL relational, SBJ subject, SG singular, SR subordinator, STAT stative, vR verbing suffix

\section{Acknowledgements}

I would like to thank the speakers of Nahuatl who struggle to preserve their language: students, scholars, teachers, activists and all other community members who contributed to this research and shared their time, knowledge and ideas with me. I am also grateful to Robert Borges, Gordon Whittaker, Matt Coler, John Sullivan and anonymous reviewers for their comments on this paper and suggestions for its improvement.

The research leading to these results has received funding from the European Research Council under the European Union's Seventh Framework Program (FP7/2007-2013)/ERC grant agreement no. 312795. It also benefited from the capacity-building and other activities of the project 'Engaged Humanities in Europe' (European Union's Horizon 2020 Twinning programme under grant agreement no. 692199). 


\section{References}

1. INEGI (Instituto Nacional de Estadística, Geografía e Informática) (2010) Censo de población y vivienda 2010. Características culturales de la población, Población hablante de lengua indígena de 5 y más años por principales lenguas. Available online at: http://www3.inegi.org.mx/sistemas/temas/default.aspx? $\mathrm{s}=\mathrm{est} \& \mathrm{c}=19004$.

2. H. Hammarström, R. Forkel, M. Haspelmath and S. Bank (2016) Glottolog 2.7 (Jena: Max Planck Institute for the Science of Human History), Available online at http://glottolog.org.

3. A. Aikhenvald (2006) Grammars in contact: A cross-linguistic perspective. In: A. Aikhenvald and R. M. W. Dixon, (eds), Grammars in Contact: A CrossLinguistic Typology. (Explorations in Linguistic Typology 4.) (Oxford: Oxford University Press), pp. 1-66.

4. N. Dorian (1981) Language Death: The Life Cycle of a Scottish Gaelic Dialect (Philadelphia: University of Pennsylvania Press)

5. N. Dorian (1986) Abrupt transmission failure in obsolescing languages: How sudden they 'tip' to the dominant language communities and families. In: V. Nikiforidu, M. V. Clay, M. Niepokuj and D. Feder, (eds.), Proceedings of the Twelfth Annual Meeting of the Berkeley Linguistics Society (Berkeley Berkeley Linguistics Society), pp. 72-83.

6. C. Grinevald (1998) Language contact and language degeneration. In: F. Coulmas, (ed.), The Handbook of Sociolinguistics (Blackwell Reference Online), pp. 176-184.

7. H.-J. Sasse (1992) Theory of language death. In M. Brenzinger, (ed.), Language Death (New York: Mouton de Gruyter), pp. 7-30.

8. Europe and America in Contact. A Multidisciplinary Study of Cross-Cultural Transfer in the New World Across Time is funded by the Starting Grant of the European Research Council (2012-2017).

9. M. Restall (2003) A History of the New Philology and the New Philology in History. Latin American Research Review, 38(1), 113-134.

10. J. Olko and J. Sullivan (2014) Toward a comprehensive model for Nahuatl language research and revitalization. Proceedings of the Fortieth Annual Meeting of the Berkeley Linguistics Society, 40, pp. 369-397.

11. J. Olko and J. Sullivan (2016) Bridging divides: A proposal for integrating the teaching, research and revitalization of Nahuatl. In: V. Ferreira and P. Bouda, (eds.), Language Documentation and Conservation Special Publication No. 9: Language Documentation and Conservation in Europe (Honolulu: University of Hawai'i Press), pp. 159-184.

12. J. Olko and J. Sullivan (2016) Bridging gaps and empowering speakers: An inclusive, partnership-based approach to Nahuatl research and revitalization. In: J. Olko, T. Wicherkiewicz and R. Borges, (eds.), Integral strategies for language revitalization (Warsaw: University of Warsaw), pp. 347-386.

13. J. Schwaller (2012) The expansion of Nahuatl as a Lingua Franca among priests in sixteenth-century Mexico. Ethnohistory, 59(4), pp. 675-676.

14. M. Christensen (2012) The use of Nahuatl in evangelization and the ministry. Ethnohistory, 59(4), pp. 691-697.

15. M. Hidalgo (2006) Language policy. Past, present, and future. In M. Hidalgo, (ed.) Mexican Indigenous Languages at the Dawn of the Twenty-First Century (Berlin, New York: Mouton de Gruyter), pp. 357-376.

16. M. Nesvig (2012) Spanish men, indigenous language, and informal interpreters in postcontact Mexico. Ethnohistory, 59(4), pp. 739-776. 
17. J. Olko (2014) Eighteenth-century provincial elites from Ixtenco, Tlaxcala, a paper presented at the Annual Conference of the American Society for Ethnohistory, Indianapolis, 12 April 2014.

18. J. Lockhart (1992) The Nahuas After the Conquest. A Social and Cultural History of the Indians of Central Mexico, Sixteenth Through Eighteenth Centuries (Stanford: Stanford University Press)

19. J. Sullivan (2007) The Jalostotitlan Petitions, 1611-1618. In J. Lockhart, L. Sousa and S. Woods, (eds.) Sources and Methods for the Study of Postconquest Mesoamerican Ethnohistory, Provisional Version (Eugene, Oregon: Wired Humanities Project; University of Oregon). http://whp.oregon.edu/Lockhart/ Sullivan.pdf.

20. J. Olko (2015) Language encounters: Toward a better comprehension of contactinduced lexical change in colonial Nahuatl. Politeja, 38, pp. 35-52.

21. J. A. Suárez (1983) The Mesoamerican Indian Languages (Cambridge: Cambridge University Press).

22. J. Hill and K. Hill (1986) Speaking Mexicano. Dynamics of Syncretic Language in Central Mexico (Tucson: University of Arizona Press).

23. J.A. Flores Farfán (1999) Cuatreros somos y toindioma hablamos. Contactos y conflictos entre el náhuatl y el español en el sur de México (Tlalpan, D.F: CIESAS).

24. A. Flores Farfán (2003) Nahuatl purism: Between language innovation, maintenance and shift. In: J. Brincat et al. (eds.) Purism in the age of globalization (Bochum: Universitätsverlag Dr. N. Brockmeyer), pp. 281-313.

25. C. O'Shanness (2011) Language contact and change in endangered languages. In: P. Austin and J. Sallabank, (eds.) The Cambridge Handbook of Endangered Languages (Cambridge: Cambridge University Press), pp. 78-99.

26. N. Palosaari and L. Campbell (2011) Structural aspects of language endangerment. In: P. Austin and J. Sallabank, (eds.), The Cambridge Handbook of Endangered Languages (Cambridge: Cambridge University Press), pp 100-119.

27. W. Dressler (2011) Early linguistic indicators of language decay. In E. Miola and P. Ramat, (eds.) Language Contact and Language Decay: Socio-political and Linguistic Perspectives (Pavia: IUSS Press), pp. 89-108.

28. Y. Matras and J. Sakel (2007) Investigating the mechanisms of pattern replication in language convergence. Studies in Language, 31(4), pp. 829-865.

29. A. Y. Aikhenvald (2006) Reflections on language contact, areal diffusion, and mechanisms of linguistic change. In: B. Caron and P. Zima, (eds.) Sprachbund in the West African Sahel (Paris: Peeters), pp. 23-36.

30. A. Bergier and J. Olko (2016) Is my Nahuatl coherent? A comparative analysis of language attitudes among modern Nahua speakers. In: J. Olko, T. Wicherkiewicz and R. Borges, (eds.) Integral strategies for language revitalization (Warsaw: University of Warsaw), pp. 297-346.

\section{About the Author}

Justyna Olko is a researcher at the Faculty of 'Artes Liberales' at the University of Warsaw, and obtained a doctoral degree in the humanities in 2005 at the UW's Faculty of History, and habilitation in ethnology at Adam Mickiewicz University in Poznań in 2016. She specializes in the ethnohistory, anthropology and linguistics of colonial and modern Mexico, with a special focus on Nahua language and culture. She is also involved in a programme for revitalizing the Nahuatl language and works with researchers and activists committed to revitalizing endangered languages of 
ethnic minorities in Poland. She is the author of several books, including Insignia of Rank in the Nahua World (University Press of Colorado, 2014), and a recipient of several major grants for team projects, including a European Research Council Starting Grant (2012), the Twinning grant of the European Commission (2015) and the Team grant (Foundation for Polish Science, 2017). She has been awarded the Knight's Cross of the Order of Polonia Restituta (2013) and a Burgen Fellowship by Academia Europaea (2013). 